\title{
The Role of the Strong Version of the Contrastive Analysis Hypothesis in Foreign Language Acquisition of Pronunciation
}

\author{
Dr. Maosheng Hung \\ Associate Professor, Department of English \\ School of Foreign Languages \\ Fuzhou University of International Studies and Trade \\ No. 28, Yuhuan Road, Shouzhan New District \\ Changle District, Fujian Province \\ PR China (zip code: 350202)
}

\begin{abstract}
This study mainly investigated the predictions of the strong version of the Contrastive Analysis Hypothesis (CAH) on Taiwanese university EFL students' acquisition of two English consonants (/s/ and /o/) by examining the learners' relative productive difficulty of the consonants. To reach the goal, a pronunciation test designed by the researcher was administered, and two research questions were formed. Fifty students from a private university in northern Taiwan were recruited to participate in this research. Their accuracy in pronouncing the tested consonants was rated via the self-designed production test. After all the participants' test scores were collected, an independent-samples $t$ test was conducted to analyse the data. The results showed that the relative productive difficulty of the two consonants for the students was $/ s /=/ \theta /$. The finding suggested that the strong version of the CAH was found invalid in predicting the participants' acquisition of the consonants in production.
\end{abstract}

Keywords: Contrastive Analysis Hypothesis (CAH), consonant, EFL, fricative, production, pronunciation, strong version

\section{Introduction}

The Contrastive Analysis Hypothesis $(\mathrm{CAH})$, originating from behaviourism and structuralism, primarily investigates two languages in contrast. It asserts that linguistic contrasts between two languages can be produced by conducting a scientific and structural analysis of the two languages and these contrasts can assist linguists in predicting the difficulties that L2 learners might encounter. One of the strongest claims regarding the CAH comes from Robert Lado (1957). In his book, Linguistics Across Cultures, Lado claims that L2 learners are inclined to transfer their L1 systems to the L2 learning process. L2 elements that are different from L1 elements are more difficult for L2 learners to acquire. In contrast, L2 elements that are similar to L1 elements are easier for L2 learners. This claim further suggests that new L2 elements are the most difficult elements for L2 learners to acquire, and similar L2 elements are the easiest.

In the past, many research studies have been conducted to examine the predictions/validity of Lado's (1957) CAH on L2/FL learning, but the results are mixed. For example, Gao (2005) analysed pronunciation problems that were encountered by a 26-year-old Chinese graduate student at an American university. The researcher used oral readings and spontaneous speech to collect speech samples of the participant's pronunciation. After listening to the student's recording many times, the researcher found that the participant had trouble pronouncing some English sounds that do not exist in the Chinese sound inventory. The finding provided evidence for the assertion that one's L1 influences or interferes with his/her acquisition of L2/FL pronunciation. In contrast, Hung (2014) evaluated the predictions of the strong version of the Contrastive Analysis Hypothesis on Taiwanese university EFL students' acquisition of two English consonants (/s/ and /e/). A pronunciation test was designed to collect data for analysis. The statistical results of the study showed that the English /s/ and /ब/ posed a similar level of difficulty for the EFL learners. Therefore, the finding did not agree with the predictions of the strong version of the CAH.

From the review of past literature above, there are pros and cons for/against the predictions/validity of the strong version of the CAH. Hence, the importance of the version in L2/FL acquisition of pronunciation is still controversial, and this is why the researcher of the current study attempted to conduct this experiment. To better understand the role that the strong version of the CAH plays in L2/FL pronunciation learning, this study aimed to examine Taiwanese university EFL students' production of two English consonants (i.e., /s/ and /e/). According to Zhang and Yin (2009), the English /s/ has a Chinese counterpart, whereas the English / $\Theta /$ does not.

If it can be confirmed that the English /s/ was easier for the Taiwanese learners to pronounce and the English / $/$ was more difficult, the strong version of the CAH is favoured. If the results show no difference in the participants' productive proficiency of the two consonants, the validity of the strong version is denied. 
To find out evidence for/against the strong version of the Contrastive Analysis Hypothesis (CAH), the following research questions were formed:

1. What is the relative productive difficulty of the two English consonants (/s/ and /e/) for Taiwanese university EFL students?

2. Is the relative productive difficulty accurately predicted by the strong version of the $\mathrm{CAH}$ ?

\section{Methods}

\subsection{Participants}

Originally, 124 Taiwanese university students who majored in applied English were recruited to participate in this study. Due to the fact that this study mainly investigated the EFL learners' accuracy in pronouncing two English consonants (i.e., $/ \mathrm{s} /$ and $/ \theta /$ ), the researcher only included students who had been learning English in Taiwan. Those who had received English instruction outside of Taiwan or had been raised in an environment where English is consistently spoken were excluded from the study. Based on the data collected, nine students mentioned that they had learned English outside of Taiwan. After removing these learners, the researcher randomly selected 50 out of the remaining 115 students as the finalized participants of this study. These participants also reported no impediments in their speaking and hearing abilities.

The 50 participants were composed of 22 males and 28 females, and they were either sophomores or juniors at the university where this study was conducted. Their ages ranged from 19 to 21 at the time of the study (mean: 19.54). In addition to these EFL learners, three native speakers of English participated in this experiment. They served as raters of a production test, and their main task was to listen to the recordings produced by the learners and identify the words they heard on an answer sheet. The three English native speakers had been teaching English at universities in Taiwan for years.

In order to guarantee the reliability among the three raters, an inter-rater reliability test was conducted. Three students who did not participate in the process of the pronunciation test were asked to take the pronunciation test. The result showed that the Intra-class Correlation Coefficient is at the level of 1.00 (see Table 1). This number demonstrated that the reliability among the raters' judgments was very high $(>.70)$.

Table 1

Inter-Rater Reliability among the Three Raters

\begin{tabular}{lccccccc}
\hline & Intraclass & \multicolumn{2}{c}{ 95\% Confidence Interval } & \multicolumn{3}{c}{ F Test with True Value 0 } \\
& Correlation & Lower Bound Upper Bound & Value & df1 & df2 & Sig. \\
\hline Single measures & 1.00 & 1.00 & 1.00 & - & 2 & - & - \\
Average measures & 1.00 & 1.00 & 1.00 & - & 2 & - & - \\
\hline
\end{tabular}

\subsubsection{Instruments}

The goal of this study was to explore the relative productive difficulty of two English fricatives $(/ \mathrm{s} /$ and $/ \theta /)$ for Taiwanese university EFL learners. The instruments used to collect data included a language learning background questionnaire and a pronunciation test.

\subsubsection{Language learning background questionnaire}

A questionnaire (see Appendix A) adopted from the one of Lin, Hung, and Wang (2016) was administered to gather information about the participants' language learning background such as the learners' name, gender, age, major/grade, hearing and speaking conditions, the environment in which they had learned the target language, and so on. Some of the questions required the students to check the most appropriate answer while others required them to fill in the blanks. The questionnaire given to the 50 participants was written in Mandarin Chinese, and it was administered before the participants took the pronunciation test.

\subsubsection{Pronunciation test}

The main goal of this study was to measure Taiwanese university EFL students' productive accuracy of two English consonants (i.e., $/ \mathrm{s} /$ and $/ \theta /$ ). Hence, a pronunciation test of the two consonants was developed. According to Zhang and Yin (2009), the English /s/ has a Chinese counterpart, but the English / $/$ / does not.

The pronunciation test consisted of 16 stimuli that were selected from 16 minimal pairs (see Appendix B). These minimal pairs were categorized into eight pairs of word-initial contrasts and eight pairs of word-final contrasts based on the position of the two consonants $(/ \mathrm{s} /$ and $/ \theta /)$ in the tested words. The words in the 16 minimal pairs were all monosyllabic words, and they were all included in the senior high school 7000 English word list announced by the Ministry of Education (MOE) in Taiwan. In addition, the two tested consonants were equally 
distributed both word-initially and word-finally among the test stimuli (see Appendix C) and among the test options on the answer sheet (see Appendix D).

\subsubsection{Scoring}

After the pronunciation test was completed, the participants' recordings were rated by three native speakers of American English. They all listened to the same recordings and then identified words they heard on a marking sheet (see Appendix D). The same response given by two or all of the native listeners for each test item was taken as the learner's actual productive performance for the tested sound. If the response was the correct answer, a point was earned by the student. The higher the score a participant received, the more accurately he or she could pronounce the two English consonants.

\subsection{Procedure}

This study proceeded in the following steps. First, the researcher recruited Taiwanese university EFL students and informed them of the purposes of the study. Then the students were asked to fill in a language learning background questionnaire. After completing the questionnaire, they were given a pronunciation test for measuring their productive accuracy of two English fricatives (/s/ and $/ \theta /$ ). When all the relevant data were gathered, the participants' personal information and their test scores were calculated and organized on Excel for further statistical analysis.

\section{Results}

To address the questions of this study, an independent-samples $t$ test was used to analyse the collected data. Table 2 and Table 3 summarize the statistical results obtained.

Table 2 displays the mean scores the 50 Taiwanese university EFL students received in pronouncing the two English fricative consonants and their overall performance on the pronunciation test. The statistical data indicate that the mean score (7.30) the participants received in producing the English consonant /s/ is higher than the score (6.96) they received in producing the English consonant $/ \theta /$. Based on these mean scores, it seems that the English consonant /s/ was easier for the EFL learners to pronounce than the English consonant $/ \theta /$.

Table 2

Mean and Standard Deviation for the Tested Consonants $(N=50)$

\begin{tabular}{ccc} 
& Mean & Standard Deviation \\
\hline$/ \mathbf{s} /$ & 7.30 & 1.25 \\
\hline$/ \boldsymbol{\theta} /$ & 6.96 & 1.47 \\
\hline Overall & 14.26 & 1.37 \\
\hline
\end{tabular}

Table 3 presents the comparison of the productive difficulty between the two English fricatives (/s/ and $/ \theta /)$ for the Taiwanese university EFL learners. The results of the independent-samples $t$ test show no significant difference between the means, $t=1.25, p>.05$. The statistical data suggest that the mean score for the English consonant $/ \mathrm{s} / \mathrm{is}$ not significantly higher than the mean score for the English consonant $/ \theta /$. That means that the two consonants posed a similar level of difficulty for the participants. Consequently, the relative productive difficulty sequence for the Taiwanese university EFL students becomes $/ \mathrm{s} /=/ \theta /$ instead of $/ \theta />^{1} / \mathrm{s} /$.

Table 3

Independent-Samples $t$ Test Results for the Mean Difference between the Scores for the Two English Consonants $(N=50)$

\begin{tabular}{lcccc}
\hline & Mean Difference & $\mathrm{t}$ & $\mathrm{DF}$ & Sig. (2-tailed) \\
\hline $\begin{array}{l}\text { Equal Variances } \\
\text { assumed }\end{array}$ & .34 & 1.25 & 98 & .22 \\
$\begin{array}{l}\text { Equal Variances } \\
\text { NOT assumed }\end{array}$ & .34 & 1.25 & 95.52 & .22 \\
\hline
\end{tabular}

${ }^{1}>$ means more difficult than 


\section{Discussion and Conclusion}

This study aimed to determine the relative productive difficulty of two English fricatives (i.e., /s/ and / $/ 9 /$ ) for 50 Taiwanese university EFL learners, followed by using the difficulty to investigate the predictions of the strong version of the Contrastive Analysis Hypothesis (CAH) in foreign language acquisition of pronunciation. To reach the goal, two research questions were formed. The answers to the questions did not support the claims of the version since the participants' production of the consonant /s/ was not significantly better than their production of the other consonant $/ \theta /$, and vice versa. The finding is consistent with the finding of Hung (2014) that the strong version of the $\mathrm{CAH}$ is invalid.

From the results above, several educational implications on L2/FL pronunciation teaching can be drawn. First, it is crucial and essential to draw learners' attention to the place and manner of articulation of each sound. To achieve the goal, students should be given professional instruction and specific training on the segmental features of the target sound. When doing this, language teachers also need to make sure that their learners will not negatively transfer the phonetic or phonological system they have acquired from their mother tongue to the system of the target language (TL) (Hung, 2018). Next, giving students sufficient time to get familiar with new sounds is also very important. If students can get enough instruction, training, and practice, they may improve their pronunciation skills little by little and then eventually become proficient in the sound system of the TL (Hung, 2018).

Regarding the limitations and delimitations of this study, due to the fact that the number of participants was 50 and they were all recruited from a single university, the results of the current research might not be generalized to students in other universities. Moreover, this study only focused on the examination of consonants. Vowels and other aspects of grammar such as suprasegmental and morphosyntactic features were not touched upon. Therefore, it is suggested that future L2/FL researchers of the same interest use a larger sample size, choose a wide range of participants, and explore various linguistic features to gain more reliability.

\section{References}

Gao, L. (2005). Pronunciation difficulties analysis: A case study — using native language linguistic background to understand a Chinese English learner's pronunciation problems. CELEA Journal, 28(2), 76-84.

Hung, M. (2012). The correlation of onset age and of instruction time in school to Taiwanese EFL learners' perception of English vowels. Taiwan Journal of TESOL (TJTESOL), 9(1), 89-124.

Hung, M. (2014). The Contrastive Analysis Hypothesis revisited: The prediction of the strong version on FLA of segments. Studies in English Language and Literature, 34, 123-152.

Hung, M. (2018). Taiwanese vocational high school EFL learners' perception and production of two English vowels and the Contrastive Analysis Hypothesis. Languages and International Studies, 19, 79-102.

Lado, R. (1957). Linguistics Across Cultures: Applied Linguistics for Language Teachers. Ann Arbor, MI: University of Michigan Press.

Lin, H. Y., Hung, M., \& Wang, H. J. (2016). The critical period hypothesis revisited: An investigation of Taiwanese university EFL learners' production of two English consonants. Arab World English Journal (AWEJ), 7(2), 417-428.

Zhang, F., \& Yin, P. (2009). A study of pronunciation problems of English learners in China. Asian Social Science,

\section{Appendix A} $5(6), 141-146$.

Dear Participant,

We would like to understand your English learning experiences. Please do us a favour by answering the following questions. The results from this research may help you and later generations of classmates learn English more effectively. The questionnaire will take 5-10 minutes for you to finish. Please try to be specific when you answer the questions. Thanks for your help.

XXX

The Researcher

\begin{tabular}{|c|c|}
\hline 1. Name: & 2. Gender: male/female \\
\hline 3. Age: & 4. Major/grade: \\
\hline
\end{tabular}

4. Major/grade:

5. Do you have any hearing or speaking impairments? $\square$ Yes $\square$ No

6. Have you ever studied or lived in an English-speaking country?

$\square$ Yes, which country:

$\square$ No 
7. Did you grow up in an environment where English is constantly spoken?

$\square$ Yes

$\square$ No

8. When did you start to receive formal English instruction? years old

9. Did you learn English before attending elementary school?

$\square$ Yes $\square$ No

10. Did you attend a public or private elementary school? $\square$ Public $\square$ Private

11. How many hours a week did you learn English in your elementary school?

घone or two $\square$ three $\square$ four $\square$ five $\square$ six $\square$ seven or more

12. Were you taught by a native speaker of English when in elementary school?

$\square$ Yes, years and months $\square$ No

13. Did you attend any English cram school or one-on-one English tutoring outside of regular school when you were an elementary school student?

口Yes, years and months; hours per week $\square$ No

14. Did you strengthen your oral skills after school when you were an elementary school student? (Ex: in church, in language centres, or by having conversations with foreigners)?

$\square$ Yes, hours per week $\square$ No

15. Did you attend a public or private junior high school? $\square$ Public $\square$ Private

16. How many hours a week did you learn English in your junior high school?

aone or two $\square$ three afour $\square$ five $\square$ six $\square$ seven or more.

17. Were you taught by a native speaker of English when in junior high school?

$\square$ Yes, years and months $\square$ No

18. Did you attend any English cram school or one-on-one English tutoring outside of regular school when you were a junior high school student?

$\square$ Yes, years and month; hours per week $\square \mathrm{No}$

19. Did you strengthen your oral skills after school when you were a junior high school student? (Ex: in church, in language centre, by having conversations with foreigners)?

$\square$ Yes, hours per week $\square$ No

20. Did you attend a public or private senior high school? $\square$ Public $\square$ Private

21. How many hours a week did you learn English in your senior high school?

cone or two $\square$ three $\square$ four $\square$ five $\square$ six $\square$ seven or more.

22. Were you taught by a native speaker of English when in senior high school?

$\square$ Yes, years and months $\square$ No

23. Did you attend any English cram school or one-on-one English tutoring outside of regular school when you were a senior high school student?

$\square$ Yes, years and months; hours per week $\square$ No

24. Did you strengthen your oral skills after school when you were a senior high school student? (Ex: in church, in language centre, or by having conversations with foreigners)?

$\square$ Yes, hours per week $\square$ No

25. Please leave your contact information:

Cell phone:

E-mail: 
This is the end of the questionnaire. Thanks again for your patience and cooperation!!!

\section{Appendix B}

\section{Minimal Pairs List}

A. Minimal pairs of initial /s/ and / $/ \theta /$

\begin{tabular}{|l|}
\begin{tabular}{ll|} 
1. surd - third & 2. sink - think \\
3. sank - thank & 4. sin - thin \\
5. sick - thick & 6. seem - theme \\
7. sought - thought & 8. sigh - thigh \\
\end{tabular} \\
\hline
\end{tabular}

B. Minimal pairs of final /s/ and / $/ /$

\begin{tabular}{|c|c|}
\hline 1. truce - truth & 2. mouse - mouth \\
\hline 3. tense - tenth & 4. Norse - north \\
\hline 5. worse - worth & 6. pass - path \\
\hline 7. mass - math & 8. kiss - kith \\
\hline
\end{tabular}

\section{Appendix C}

\section{Pronunciation Test}

(Stimuli for Participants to Read)

1. mouse

2. third

3. truth

4. sink

5.tenth

6. worse

7. thank

8. north

9. $\sin$

10. sick

11. path

12. mass

13. theme

14. thought

15. kiss

16. sigh

\section{Appendix D}

\section{Marking Sheet}

(For Native Judges Use)

1. mouse / mouth 
2. third / surd

3. truth / truce

4. sink / think

5. tenth / tense

6. worse / worth

7. thank / sank

8. north / Norse

9. $\sin /$ thin

10. sick / thick

11. path / pass

12. mass / math

13. theme / seem

14. thought / sought

15. kiss / kith

16. sigh / thigh 